\title{
Topical calcineurin inhibitors in dermatology. Part I: Properties, method and effectiveness of drug use
}

\author{
Katarzyna Gutfreund, Wojciech Bienias, Anna Szewczyk, Andrzej Kaszuba
}

Department of Dermatology, Pediatric Dermatology and Dermatological Oncology, Medical University of Lodz, Poland Head: Prof. Andrzej Kaszuba MD, PhD

Postep Derm Alergol 2013; XXX, 3: 165-169

DOI: $10.5114 /$ pdia.2013.35619

\begin{abstract}
Topical calcineurin inhibitors $(\mathrm{TCl})$ are a relatively new class of drugs used in dermatology. There are two drug forms available - tacrolimus $0.03 \%$ or $0.1 \%$ ointment and $1.0 \%$ pimecrolimus cream. The drugs act by inhibiting synthesis of proinflammatory cytokines. The only approved indication for using $\mathrm{TCl}$ is treatment of atopic dermatitis. The TCI may be used as an alternative therapy to corticosteroids. Tacrolimus is used to treat moderate-to-severe atopic dermatitis, pimecrolimus - mild-to-moderate atopic dermatitis. Topical calcineurin inhibitors do not cause skin atrophy and the drug absorption through the skin is minimal. The TCI have been well-studied, their efficacy was evaluated in a number of vast, long-term studies. The anti-inflammatory potency of tacrolimus ointment is similar to a corticosteroid with moderate activity, while the latter is clearly more active than pimecrolimus cream. Topical calcineurin inhibitors significantly relieve pruritus in atopic eczema.
\end{abstract}

Key words: topical calcineurin inhibitors, tacrolimus, pimecrolimus.

\section{Introduction}

The history of calcineurin inhibitors is associated with search for immunosuppressive drugs for transplantation. Cyclosporine A was the first introduced calcineurin. Transplants of kidneys, liver, lungs or heart were possible due to drug inhibition of immune reaction against the transplanted organ. Improvement in clinical presentation of skin was observed in patients with psoriasis, atopic dermatitis and other dermatoses when given cyclosporine A after the organ transplant. Cyclosporine A is still used in treating some severe skin conditions but in transplantation it was replaced by tacrolimus, isolated in 1984, for its 10-100 times higher immunosuppressive activity [1]. Tacrolimus is produced by a type of soil bacterium Streptomyces tsukubaensis in the Tsukuba region of Japan. First known as FK 506, then the name tacrolimus was derived from Tsukuba (the mountain the soil sample came from), macrolide (the compound is a hydrophobic macrolide) and immunosuppressive [1, 2]. Tacrolimus was introduced as an oral drug preventing transplant rejection in 1989. Despite several attempts to treat atopic dermatitis, psoriasis, alopecia areata, pemphigus or eosinophil fasciitis with the drug, it is not commonly used in systemic treatment in derma- tology, which may be due to its high costs [3]. Discovery of pimecrolimus, another calcineurin inhibitor, resulted from long studies on ascomycin derivatives (antifungal and immunomodulatory compound) in the Laboratory of Novartis. Pimecrolimus, ascomycin macrolactam, is produced by the fermentation of Streptomyces hygroscopicus var. ascomycetous.

Tacrolimus (topical) was launched on the market at the end of 2000, pimecrolimus in 2001. Attempts of topical use of cyclosporine A were not successful due to high molecular weight (about $1200 \mathrm{Da}$ ), preventing effective penetration into the skin [4]. Sporadically, the drug is used in the form of eye drops in eye inflammation and for washing the oral cavity in patients with pemphigus vulgaris [5, 6]. Tacrolimus and pimecrolimus have similar both chemical structure and molecular mass (about $800 \mathrm{Da}$ ). The molecular structure allows effective skin penetration, not as intense as topical glucocorticosteroids, which prevents higher systemic drug absorption [7].

\section{Mechanism of action of calcineurin inhibitors}

Mechanism of action of calcineurin inhibitors is suppressing synthesis of pro-inflammatory cytokines. In the

Address for correspondence: Prof. Andrzej Kaszuba MD, PhD, Department of Dermatology, Pediatric Dermatology and Dermatological Oncology, Medical University of Lodz, 1/5 Kniaziewicza St, 91-347 Lodz, Poland, phone: +48 42651 10 72, e-mail: andrzej.kaszuba@umed.lodz.pl Received: 15.03.2013, accepted: 4.06.2013. 
cytoplasm of the target cells, pimecrolimus and tacrolimus bind to the intracellular protein macrophilin-12, also called FKBP (FK506-binding protein). Similarly, cyclosporine A binds to cyclophilin. Immunosuppressive activity results from suppressing calcineurin activity - dependent on calcium and calmodulin (serine-threonine phosphatase). The drug has an anti-inflammatory activity due to T-helper activity affecting synthesis and release of pro-inflammatory cytokines. Cytokine transcription blockage leads to decrease in expression of cytokine Th1 and Th2 dependent among others on interleukin 2, 3, 4 and 5 (IL-2, IL-3, IL-4, IL-5), interferon- $\gamma$ (INF- $\gamma$ ) and tumor necrosis factor- $\alpha$ (TNF- $\alpha$ ). Tacrolimus and pimecrolimus inhibit mast cell and neutrophil activation and release of inflammatory mediators. Tacrolimus affects basophils and eosinophils function as well as function and apoptosis induction of Langerhans cells $[7,8]$.

\section{Indications for use of topical calcineurin inhibitors}

Tacrolimus is available in the form of $0.1 \%$ and $0.03 \%$ ointment (Protopic) while pimecrolimus in the form of $1 \%$ cream (Elidel). The only approved indication for use of topical calcineurin inhibitors (TCI) is atopic dermatitis (AD). However, these preparations are also very effective in treating other dermatoses, particularly seborrheic dermatitis, genital lichen sclerosus, oral lichen planus, psoriasis (face and flexures areas), vitiligo and alopecia areata [9, 10].

Tacrolimus is used for treating moderate-to-severe $A D$ when there is no sufficient response or tolerance to conventional treatment, such as topical use of corticosteroids. The drug was also approved for supportive therapy (proactive therapy) of moderate-to-severe $A D$ to prevent relapses and extend periods without recurrence in patients with frequent exacerbations (4 or more times a year) and who initially used to respond to treatment with tacrolimus ointment 2 times a day for maximum 6 weeks.
The new proactive therapy has been based on new discoveries in AD pathogenesis. In the course of this inflammatory dermatosis, disorders affecting both the structure and immune function are observed in seemingly unchanged skin. They are reported to be significantly dependent on filaggrin gene mutation. After disappearance of active lesions, the skin still presents features of subclinical inflammation [11].

In remission tacrolimus should be applied on the skin area where most intense lesions were observed in the course of the last exacerbation or where lesions usually appear, one or two times a day for 2 days a week (e.g. Monday and Thursday). Significant effectiveness of proactive therapy in preventing AD exacerbations and lower cost compared with conventional reactive treatment are stressed [12]. So far proactive therapies for the described tacrolimus as well as for two glucocorticosteroids: fluticasone and methylprednisolone have been investigated [11].

Pimecrolimus was approved for mild-to-moderate AD when topical corticosteroids are contraindicated or not tolerated. Pimecrolimus in proactive therapy has not been studied.

Both topical calcineurin inhibitors were approved for $2+$ years. Pimecrolimus should be applied on lesions two times a day until they subside, but not longer than 6 weeks. Tacrolimus (0.03\%) is indicated for patients between 2 and 16 years and is applied 2 times a day for 3 weeks and then one time a day until disappearance of symptoms. Tacrolimus (0.1\%) is for $16+$ years, applied 2 times a day until disappearance of symptoms (Table 1 ).

\section{Glucocorticosteroids and topical calcineurin inhibitors}

Topical calcineurin inhibitors should be used as a second-line drugs following topical glucocorticosteroids (GCs), which are regarded as topical treatment "gold standard" for the disease exacerbations [13]. The great advan-

Table 1. The use of tacrolimus and pimecrolimus

\begin{tabular}{ll}
\hline Tacrolimus & Pimecrolimus \\
\hline - Treatment of moderate-to-severe AD in case there is no sa- & - Mild-to-moderate AD when topical corticosteroids are not \\
tisfactory response or no tolerance to conventional treatment, & $\begin{array}{c}\text { recommended or not possible } \\
\text { such as topical corticosteroids }\end{array}$ \\
- From 2 to 16 years, first $0.03 \%$ ointment twice daily for & until lesions disappear, not longer than 6 weeks \\
& 3 weeks, then once daily until disappearance of lesions \\
- From 16 years, $0.1 \%$ ointment until disappearance of lesions & \\
- Supportive treatment of moderate-to-severe AD to prevent \\
recurrence and extend periods without recurrence in patients \\
with frequent exacerbations (4 or more times a year) who \\
initially responded to treatment with tacrolimus ointment \\
twice daily for max. 6 weeks \\
- Use once daily 2 days a week (e.g. Monday and Thursday) \\
on the affected surface \\
0.1\% ointment in adults, $0.03 \%$ in children
\end{tabular}


Table 2. Mechanism of action of pimecrolimus, tacrolimus and topical corticosteroids

\begin{tabular}{|c|c|c|c|}
\hline Parameter & Pimecrolimus & Tacrolimus & Corticosteroids \\
\hline Activity on cells & $\begin{array}{l}\text { T lymphocytes } \\
\text { Mast cells }\end{array}$ & $\begin{array}{l}\text { T lymphocytes } \\
\text { Mast cells } \\
\text { Eosinophils, basophils } \\
\text { Langerhans cells }\end{array}$ & $\begin{array}{l}\text { T lymphocytes } \\
\text { Mast cells } \\
\text { Eosinophils, basophils } \\
\text { Langerhans cells } \\
\text { Keratinocytes } \\
\text { Endothelial cells } \\
\text { Fibroblasts }\end{array}$ \\
\hline Cytokines & $\begin{array}{l}\text { IL-2, IL-3, IL-4, } \\
\text { IL-5, INF- } \gamma \text {, TNF- } \alpha\end{array}$ & $\begin{array}{l}\text { IL-2, IL-3, IL-4, } \\
\text { IL-5, INF- } \gamma \text {, TNF- } \alpha\end{array}$ & $\begin{array}{l}\text { IL-2, IL-3, IL-4, IL-5, } \\
\text { INF- } \gamma \text {, TNF- } \alpha \text {, INF- } \alpha, \text { GM-CSF }\end{array}$ \\
\hline $\begin{array}{l}\text { Function of blocking and } \\
\text { apoptosis of Langerhans cells }\end{array}$ & - & + & ++ \\
\hline Absorption through the skin & + & ++ & +++ \\
\hline Atrophogenic activity & - & - & +++ \\
\hline
\end{tabular}

tage of topical glucocorticosteroids is their fast and effective action, however, there are adverse effects to be considered. Long-term use of GCs may lead to skin atrophy, telangiectasia, striae, hyper- and hypopigmentation, as well as to anaphylaxis and contact allergy. In extreme cases, excessive overuse of topical GCs may cause hypothalamicpituitary-adrenal suppression, induce Cushing's syndrome. There were cases of developing glaucoma in children following GCS application on the lid [14]. In contrast, $\mathrm{TCl}$ due to their high affinity for the receptor and lower absorption through skin do not cause such symptoms. The $\mathrm{TCl}$ are especially indicated in long-term therapies or areas such as the face, folds and genital region, where penetration through skin is many times higher [13].

The $\mathrm{TCl}$ do not have atrophogenic activity as they affect neither endothelial cells nor fibroblasts like topical GCs. Target cells for pimecrolimus are T lymphocytes, mast cells, whereas for tacrolimus - $\mathrm{T}$ lymphocytes, mast cells, eosinophils, basophils and most importantly Langerhans cells [7]. Kyllönen et al. found that long-term therapy with tacrolimus leads to withdrawal of steroid-dependent skin atrophy and increase in collagen synthesis and skin thickness [15] (Table 2).

\section{Pharmacokinetics of topical calcineurin inhibitors}

The $\mathrm{TCl}$ absorption through the skin into circulation is minimal due to a large molecular size of the drugs. The highest absorption is observed in the initial stage of AD treatment when the inflammatory process is most advanced. When the disease subsides and epidermal barrier recovers, penetration into the skin decreases [16]. Increased tacrolimus penetration into circulation was found in dermatoses where profound skin barrier damage is observed e.g. Netherton syndrome [17], lamellar ichthyosis [18], pyoderma gangrenosum [19]. Pimecroli- mus is more lipophilic than tacrolimus, which results in slow penetration of $\mathrm{TCl}$ from the corneal layer rich in lipids into the hydrated lower epidermal layer [20]. The TCI penetrates much lower than topical glucocorticosteroids [21].

Draelos et al. compared pimecrolimus and tacrolimus concentrations in the blood from patients given one of the preparations 2 times a day for 13 days. Tacrolimus was detectable in $36 \%$ of blood samples whereas pimecrolimus in $12 \%$ and the concentration was very low. Subsequent studies on $\mathrm{TCl}$ pharmacokinetics confirmed very low absorption into systemic circulation [22]. Undre et al. evaluated tacrolimus distribution in the skin and serum after application on the extended surface of the skin. Gradual decrease in the drug concentration in the skin along with the increasing skin depth was found, moreover, the retention time was short after the drug withdrawal. Systemic drug activity was not confirmed; in 64\% of patients the concentration was below $1 \mathrm{ng} / \mathrm{ml}$, and in $30 \%$ it was undetectable [23]. Pharmacokinetic studies on pimecrolimus carried out on children with moderate-to-severe $A D$ and whose body surface was affected up to $92 \%$, showed $67 \%$ of pimecrolimus blood concentrations below $0.5 \mathrm{ng} / \mathrm{ml}$ and $97 \%$ of samples did not exceed $2.0 \mathrm{ng} / \mathrm{ml}$ [24]. In a recent study carried out on a group of very young children (between 3 and 24 months) given $0.03 \%$ tacrolimus 2 times daily for 2 years in exacerbation, the concentration of tacrolimus was $<1.0 \mathrm{ng} / \mathrm{ml}$ in $98 \%$ of blood samples and in $>40 \%$ of blood samples, tacrolimus concentration was below the limit of detection (0.0250 ng/ml) [25].

In the investigated groups of children there was no difference in drug absorption through skin depending on age. No increased risk of systemic or local infection was found. Proper immune response to vaccination in the course of treatment with $\mathrm{TCl}$ was observed, which confirms only topical activity of the drug [26]. 


\section{Efficacy of topical calcineurin inhibitors}

The $\mathrm{TCl}$ are a well-investigated class of drugs, their efficacy was assessed in many longitudinal studies on vast populations of patients. First clinical reports on topical tacrolimus and pimecrolimus described the drug significant efficacy in the management of patients with AD.

In the study on a group of 624 children with moderateto-severe AD, Reitamo et al. found that $0.03 \%$ tacrolimus ointment is more effective than $1 \%$ hydrocortisone acetate [27]. The following investigations carried out by Remitz et al. on a group of 466 children at the age of 2-15 years for 30 months showed effectiveness of tacrolimus in $A D$ management [28]. In 2008, results from a multi-centre study on the effectiveness and safety of tacrolimus use, conducted on a group of 782 patients with $A D$ at the age between 2 and 72 years, were published. The treatment was stopped when all skin lesions and pruritus disappeared, in the case of recurrence, the therapy was restarted. After 4 weeks' therapy, $60 \%$ of patients or their caretakers evaluated the clinical picture as very good or excellent. In the final stage $75 \%$ of participants of the study were satisfied with the treatment [29].

The obtained results from the studies on effectiveness of pimecrolimus are also satisfying. In a double-blind study on a group of 713 children between 2 and 17 years with AD carried out for 12 months, Wahn et al. compared effectiveness of treatment with pimecrolimus to conventional topical methods (glucocorticosteroids, emollients). Clinical evaluation was performed after 6 and 12 months of treatment, safety and tolerance to the preparations were also monitored; improvement in the clinical picture was found after both 6 and 12 months of the treatment [30]. In the comparative study of pimecrolimus and the drug vehicle, Kaufmann et al. proved significant reduction in pruritus; improvement was observed in $56 \%$ of patients applying pimecrolimus and $34 \%$ of patients given placebo [31]. Reduction in pruritus after using 1\% pimecrolimus was also found in a study on 186 children with mild-to-moderate AD conducted by Ho et al. [32]. In the study on adult patients with AD, Meurer et al. found decrease in Eczema Area and Severity Index (EASI) by $33 \%$ in the first 7 days and by $69.8 \%$ in the $6^{\text {th }}$ week of treatment with pimecrolimus. In contrast, there was an increase in EASI by $3.8 \%$ in the first week and by $15.9 \%$ in the $6^{\text {th }}$ week in the control group using drug vehicle [33].

Paller et al. conducted comparative studies on effectiveness of tacrolimus and pimecrolimus in children and adult patients with AD. Randomized single-blinded studies were carried out on 1065 patients for 6 weeks by three multistudy centres. The obtained results suggest that tacrolimus was significantly more effective than pimecrolimus in EASI both in children and adult patients with moderateto-severe AD. Tacrolimus action started earlier compared with pimecrolimus [34].

Studies indicate that anti-inflammatory activity of tacrolimus may be compared with activity of medium poten- cy corticosteroids while activity of pimecrolimus is less potent than that of tacrolimus. Both $\mathrm{TCl}$ are effective in pruritus reduction, which is a great advantage in treating patients with AD suffering from this symptom [13].

\section{References}

1. Ruzicka T, Assmann T, Homey B. Tacrolimus: the drug for the turn of the millennium? Arch Dermatol 1999; 135: 574-80.

2. Gupta AK, Adamiak A, Chow M. Tacrolimus: a review of its use for the management of dermatoses. J Eur Acad Dermatol Venereol 2002; 16: 100-14.

3. Tharp MD. Calcineurin inhibitors. Dermatol Ther 2002; 15 : 325-32.

4. Surber C, Itin P, Büchner S. Clinical controversy on the effect of topical cyclosporin: what is the target site? Dermatology 1992; 185: 242-5.

5. Brown MM, Brown GC, Brown HC, et al. Value-based medicine, comparative effectiveness, and cost-effectiveness analysis of topical cyclosporine for the treatment of dry eye syndrome. Arch Ophthalmol 2009; 127: 146-52.

6. Pacor ML, Biesi D, Carleto A, et al. Topical cyclosporine in the treatment of oral pemphigus. Minerva Stomatol 1998; 47: 183-6.

7. Nghiem P, Pearson G, Langley RG. Tacrolimus and pimecrolimus: from clever prokaryotes to inhibiting calcineurin and treating atopic dermatitis. J Am Acad Dermatol 2002; 46: 228-41.

8. Gisondi P, Ellis CN, Girolomoni G. Pimecrolimus in dermatology: atopic dermatitis and beyond. Int I Clin Pract 2005; 59: 969-74.

9. Wollina $U$. The role of topical calcineurin inhibitors for skin diseases other than atopic dermatitis. Am J Clin Dermatol 2007; 8: 157-73.

10. Silny W, Sadowska A, Dańczak-Pazdrowska A, Polańska A. Application of tacrolimus in the treatment of skin diseases other than atopic dermatitis. Postep Derm Alergol 2011; 28: 41-5.

11. Wollenberg A, Bieber T. Proactive therapy of atopic dermatitis - an emerging concept. Allergy 2009; 64: 276-8.

12. Healy E, Bentley A, Fidler C, et al. Cost-effectiveness of tacrolimus ointment in adults and children with moderate and severe atopic dermatitis: twice-weekly maintenance treatment vs. standard twice-daily reactive treatment of exacerbations from a third party payer (U.K. National Health Service) perspective. Br J Dermatol 2011; 164: 387-95.

13. Ring J, Alomar A, Bieber T, et al. Guidelines for treatment of atopic eczema (atopic dermatitis) part I. J Eur Acad Dermatol Venereol 2012; 26: 1045-60.

14. Garrott HM, Walland MJ. Glaucoma from topical corticosteroids to the eyelids. Clin Exp Ophthalmol 2004; 32: 224-6.

15. Kyllönen H, Remitz A, Mandelin JM, et al. Effects of 1-year intermittent treatments with topical tacrolimus monotherapy on skin collagen synthesis in patients with atopic dermatitis. Br J Dermatol 2004; 150: 1174-81.

16. Rustin MH. The safety of tacrolimus ointment for the treatment of atopic dermatitis: a review. Br J Dermatol 2007; 157: 861-73.

17. Allen A, Siegfried E, Silverman R, et al. Significant absorption of topical tacrolimus in 3 patients with Netherton syndrome. Arch Dermatol 2001; 137: 747-50. 
18. Allen DM, Esterly NB. Significant systemic absorption of tacrolimus after topical application in a patient with lamellar ichthyosis. Arch Dermatol 2002; 138: 1259-60.

19. Pitarch G, Torrijos A, Mahquijes L, et al. Systemic absorption of topical tacrolimus in pyoderma gangrenosum. Acta Derm Venereol 2006; 86: 64-5.

20. Billich A, Aschauer H, Aszodi A, et al. Percutaneous absorption of drugs used in atopic eczema: pimecrolimus permeates less through skin than corticosteroids and tacrolimus. Int J Pharm 2004; 269: 29-35.

21. Weiss HM, Fresneau M, Moenius T, et al. Binding of pimecrolimus and tacrolimus to skin and plasma proteins: implications for systemic exposure after topical application. Drug Metab Dispos 2008; 36: 1812-8.

22. Draelos Z, Nayak A, Pariser D, et al. Pharmacokinetics of topical calcineurin inhibitors in adult atopic dermatitis: a randomized, investigator-blind comparison. J Am Acad Dermatol 2005; 53: 602-9.

23. Undre NA, Moloney FJ, Ahmadi S, et al. Skin and systemic pharmacokinetics of tacrolimus following topical application of tacrolimus ointment in adult with moderate to severe atopic dermatitis. Br J Dermatol 2009; 160: 665-9.

24. Hultsch T, Kapp A, Spergel J. Immunomodulation and safety of topical calcineurin inhibitors for the treatment of atopic dermatitis. Dermatology 2005; 211: 174-87.

25. Mandelin JM, Rubins A, Remitz A, et al. Long-term efficacy and tolerability of tacrolimus $0.03 \%$ ointment in infants: a two-year open-label study. Int I Dermatol 2012; 51: 104-10.

26. Hofman T, Cranswick N, Kuna P, et al. Tacrolimus ointment does not affect the immediate response to vaccination, the generation of immune memory, or humoral and cell-mediated immunity in children. Arch Dis Child 2006; 91: 905-10.

27. Reitamo S, Harper J, Bos JD, et al. 0.03\% Tacrolimus ointment applied once or twice daily is more efficacious than $1 \%$ hydrocortisone acetate in children with moderate to severe atopic dermatitis: results of a randomized double-blind controlled trial. Br J Dermatol 2004; 150: 554-62.

28. Remitz A, Harper J, Rustin M, et al. Long-term safety and efficacy of tacrolimus ointment for the treatment of atopic dermatitis in children. Acta Derm Venereol 2007; 87: 54-61.

29. Reitamo S, Rustin M, Harper J, et al. 0.1\% Tacrolimus Ointment Long-term Follow-up Study Group. A 4 year followup study of atopic dermatitis therapy with $0.1 \%$ tacrolimus ointment in children and adult patients. Br I Dermatol 2008; 159: 942-51.

30. Wahn U, Bos JD, Goodfield M, et al. Efficacy and safety of pimecrolimus cream in the long-term management of atopic dermatitis in children. Pediatrics 2002; 110: e2.

31. Kaufmann R, Bieber T, Helgesen AL, et al. Onset of pruritus relief with pimecrolimus cream $1 \%$ in adult patients with atopic dermatitis: a randomized trial. Allergy 2006; 61: 375-81.

32. Ho VC, Gupta A, Kaufmann R, et al. Safety and efficacy of nonsteroid pimecrolimus cream $1 \%$ in the treatment of atopic dermatitis in infants. J Pediatr 2003; 142: 155-62.

33. Meurer M, Fartasch M, Albrecht G, et al. Long-term efficacy and safety of pimecrolimus cream $1 \%$ in adults with moderate atopic dermatitis. Dermatology 2004; 208: 365-72.

34. Paller AS, Lebwohl M, Fleischer AB, et al. Tacrolimus ointment is mor effective than pimecrolimus cream with a similar safety profile in the treatment of atopic dermatitis: results from 3 randomized, comparative studies. J Am Acad Dermatol 2005; 52: 810-22. 